\title{
Trend analysis of antibiotics consumption using WHO AWaRe classification in tertiary care hospital
}

\author{
Ankit Bhardwaj*, Kaveri Kapoor, Vivek Singh
}

Saraswathi institute of Medical Sciences, Pilakhuwa, Hapur, Uttar Pradesh, India

Received: 21 August 2020

Accepted: 21 September 2020

*Correspondence:

Dr. Ankit Bhardwaj,

Email: drankitbhardwaj25@gmail.com

Copyright: () the author(s), publisher and licensee Medip Academy. This is an open-access article distributed under the terms of the Creative Commons Attribution Non-Commercial License, which permits unrestricted non-commercial use, distribution, and reproduction in any medium, provided the original work is properly cited.

\section{ABSTRACT}

Background: Aim of the study was to assess trend in antibiotics consumption pattern from 2016 to 2019 using AWaRe classification, ATC and Defined daily dose methodology (DDD) in a tertiary care hospital. Antibiotics are crucial for treating infectious diseases and have significantly improved the prognosis of patients with infectious diseases, reducing morbidity and mortality. The aim of the study is to classify the antibiotic based on WHO AWaRe classification and compare their four-year consumption trends. The study was conducted at a tertiary care center, Pilakhuwa, Hapur. Antibiotic procurement data for a period of 4 years (2016-2019) was collected from the Central medical store.

Methods: This is a retrospective time series analysis of systemic antibiotics with no intervention at patient level. Antibiotic procurement was taken as proxy for consumption assuming that same has been used. ATC for systemic use (ATC code J01) antibacterial was used and defined daily dose (DDD) per 100 bed days was calculated. Antibiotics were further classified as Access, Watch, and Reserve (WHO AWaRe classification). Antibiotics consumption was ranked based on their volume of DDD i.e., drug utilization (DU90\%) was calculated. Nonparametric Pearson's correlation coefficient was used for the comparison of consumption.

Results: Mean antibiotic procurement increased 1.25 folds from 140.3 DDD in 2016 to 201 DDD in 2018. A significant fall was seen in total DDDs in year 2019 (p value <0.05). A total of 41 antibiotics agents (Access 12 , Watch 21, Reserve 6 and Not recommended 2) were procured. Reserve category antibiotics were procured from 2017 onwards. Out of 41 antibiotics procured 11 antibiotics (Access 3 and watch 8) accounted for DU $90 \%$.

Conclusions: Antibiotics consumption of watch group was high and increasing antibiotic consumption trend was observed. Hospital antimicrobial stewardship program should be implemented to shift to use of Access group antibiotics and restrict use of Watch antibiotics.

Keywords: Antibiotics, AWaRe classification, ATC Classification, Defined daily dose

\section{INTRODUCTION}

Antibiotics consumption in India is among the highest in the world. Antibiotic procured in India increased from $3 .^{2}$ billion DDDs (defined daily doses) in 2000 to 6.5 billion DDDs in 2015. Although per-capita procurement of antibiotics in India is low when compared to several other countries Klein et al 2018. ${ }^{1}$ In the year 2019, India has scored highest of 41 countries on the drug resistance index, a measure combining both antibiotic use and resistance levels and by 2050, antimicrobial resistance has been forecast to claim on additional two million lives per year. Antimicrobial stewardship is recommended as a means of preserve effectiveness of last resort antibiotics, reducing antimicrobial resistance, along with lowering the risk of adverse drug events, treatment complications, and institutional costs. McElny et al, MacDougal et al 2005 . $^{2,3}$ To optimize the use of antimicrobials, the world health organization (WHO) in 2019 updated the essential medicine list (EML) and categorized the antibiotics into 
three groups- Access, Watch, Reserve and Not recommended (AWaRe) Sharlend et al 2018. ${ }^{4}$ It is important for institutions to understand their patterns of antimicrobial use to identify and design appropriate stewardship interventions that have the greatest likelihood of impacting institutional antimicrobial utilization and the consequences of antimicrobial resistance.

In this study we assessed the antibiotics consumption in our institute using AWaRe classification to identify issues of inappropriate antibiotic use and develop more specific guidelines for antibiotic stewardship activities.

\section{METHODS}

\section{Study design}

This is a retrospective time series analysis of systemic antimicrobial ( $\mathrm{J} 01)$ procured in a 500 bedded tertiary care hospital in Pilakhuwa, Hapur. Trends analysis of antimicrobial procured was done from 2016-2019. The procurement data for antibiotics was obtained from the Central medical store for the years 2016 -2019. Antimicrobial procurement was used as a proxy for antimicrobial consumption assuming that the same has been dispensed to patients.
Antimicrobials drugs were coded on the basis of Anatomical Therapeutic Chemical (ATC) classification and antibiotics for systemic use (ATC code J01) were considered. These were further classified as Access, Watch and Reserve (AWaRe classification) (WHO EMLc 2019). ${ }^{8}$ The amount of antimicrobial drug in grams was converted into the number of defined daily (DDDs)/100 bed-days using AMC Tool 2019.

To test the quality of use, antibiotics procured was ranked based on their volume of DDD and accounted for drug utilization $90 \%$ (DU 90\%) of total antibiotics procured. Proportion of DDD spent on according to AWaRe classification was determined.

No ethical committee approval was required for the work done.

\section{RESULTS}

\section{Statistical analysis}

Aggregated data that have been used were limited to systemic antibiotics (J01) only. Each antibiotic procured were explored for trend over time using linear regression and $\mathrm{p}$ value $\left(\mathrm{r}^{2}>0.3, \mathrm{p} \leq 0.05\right)$ consider statistically significant.

Table 1: AWaRe classification with DDD/100 bed-days in procured antibiotics over the year 2016-19.

\begin{tabular}{|c|c|c|c|c|c|c|c|c|c|c|}
\hline Access & ATC & AWaRe & $\begin{array}{l}\text { WHO } \\
\text { DDD }\end{array}$ & 2016 & 2017 & 2018 & 2019 & $\begin{array}{l}\text { Aver- } \\
\text { age }\end{array}$ & $\begin{array}{l}\text { Percent } \\
\text {-age }\end{array}$ & $\begin{array}{l}\text { DU- } \\
90 \%\end{array}$ \\
\hline Amoxycillin & J01CA04 & Access & 1 & 22.11 & 25.33 & 39.50 & 14.76 & 25.43 & 16.15 & 16.15 \\
\hline Azithromycin & J01FA10 & Watch & 0.3 & 12.24 & 19.98 & 27.52 & 21.78 & 20.38 & 12.94 & 29.09 \\
\hline Ciprofloxacin & J01MA02 & Watch & 1 & 18.63 & 20.37 & 22.27 & 19.81 & 20.27 & 12.88 & 41.97 \\
\hline $\begin{array}{l}\text { Amoxycillin } \\
\text { Clavulanic acid }\end{array}$ & J01CR02 & Access & 1.5 & 22.35 & 15.71 & 25.85 & 14.55 & 19.61 & 12.46 & 54.43 \\
\hline Doxycycline & J01AA02 & Access & 1 & 15.24 & 15.85 & 19.45 & 12.12 & 15.66 & 9.95 & 64.38 \\
\hline Cefixime & J01DD08 & Watch & 4 & 11.27 & 14.63 & 15.54 & 13.45 & 13.72 & 8.72 & 73.09 \\
\hline Ceftriaxone & J01DD04 & Watch & 3 & 10.65 & 11.34 & 15.40 & 14.73 & 13.03 & 8.28 & 81.37 \\
\hline $\begin{array}{l}\text { Erythromycin } \\
\text { (as Stearate) }\end{array}$ & JO1FA08 & Watch & 1 & 3.22 & 3.55 & 5.83 & 3.74 & 4.09 & 2.60 & 83.97 \\
\hline Ofloxacin & J01MA01 & Watch & 0.4 & 4.89 & 4.17 & 3.58 & 2.62 & 3.82 & 2.42 & 86.39 \\
\hline Norfloxacin & J01MA06 & Watch & 0.8 & 2.12 & 4.18 & 5.38 & 2.22 & 3.48 & 2.21 & 88.60 \\
\hline Levofloxacin & J01MA12 & Watch & 0.5 & 2.42 & 3.01 & 5.08 & 1.16 & 2.92 & 1.85 & 90.45 \\
\hline Cloxacillin & J01CF02 & Access & 1 & 2.67 & 3.88 & 1.09 & 0.78 & 2.11 & 1.34 & 91.79 \\
\hline Ampicillin & J01CA01 & Access & 2 & 2.64 & 3.09 & 1.71 & 0.73 & 2.04 & 1.30 & 93.09 \\
\hline Metronidazole & J01XD01 & Access & 1.5 & 1.45 & 2.16 & 1.82 & 1.69 & 1.78 & 1.13 & 94.22 \\
\hline $\begin{array}{l}\text { Ciprofloxacin + } \\
\text { Tinidazole }\end{array}$ & J01RA11 & Watch & 1.2 & 1.62 & 1.74 & 1.54 & 1.46 & 1.59 & 1.01 & 95.23 \\
\hline $\begin{array}{l}\text { Ofloxacin + } \\
\text { Ornidazole }\end{array}$ & J01RA09 & Watch & 0 & 1.53 & 1.34 & 1.53 & 1.34 & 1.44 & 0.91 & 96.14 \\
\hline $\begin{array}{l}\text { cefuroxime } \\
\text { axetil }\end{array}$ & J01DC02 & Watch & 4 & 0.93 & 1.15 & 2.39 & 0.22 & 1.17 & 0.75 & 96.88 \\
\hline Nitrofurantoin & J01XE01 & Access & 1.2 & 0.96 & 1.21 & 0.96 & 1.44 & 1.14 & 0.72 & 97.61 \\
\hline Clindamycin & JO1SA02 & Access & 1.2 & 0.85 & 1.01 & 1.52 & 0.92 & 1.08 & 0.68 & 98.29 \\
\hline $\begin{array}{l}\text { Sulfamethoxaz } \\
\text { ole+ } \\
\text { Trimethoprim }\end{array}$ & J01EC01 & Access & 2 & 0.97 & 0.80 & 1.30 & 0.65 & 0.93 & 0.59 & 98.88 \\
\hline
\end{tabular}




\begin{tabular}{|c|c|c|c|c|c|c|c|c|c|c|}
\hline Access & ATC & AWaRe & $\begin{array}{l}\text { WHO } \\
\text { DDD }\end{array}$ & 2016 & 2017 & 2018 & 2019 & $\begin{array}{l}\text { Aver- } \\
\text { age }\end{array}$ & $\begin{array}{l}\text { Percent } \\
\text {-age }\end{array}$ & $\begin{array}{l}\text { DU- } \\
\mathbf{9 0 \%}\end{array}$ \\
\hline Amikacin & J01GB06 & Access & 1 & 0.45 & 0.41 & 0.65 & 0.61 & 0.53 & 0.34 & 99.22 \\
\hline Clarithromycin & J01FA09 & Watch & 1 & 0.53 & 0.51 & 0.41 & 0.15 & 0.40 & 0.25 & 99.47 \\
\hline Rifaximin & A07aa11 & Watch & 0.4 & 0.14 & 0.12 & 0.18 & 0.14 & 0.15 & 0.09 & 99.57 \\
\hline Gentamicin & J01GB03 & Access & 0.24 & 0.10 & 0.09 & 0.15 & 0.13 & 0.12 & 0.07 & 99.64 \\
\hline Linezolid & J01XX08 & Reserve & 0.5 & 0.00 & 0.05 & 0.26 & 0.11 & 0.11 & 0.07 & 99.71 \\
\hline $\begin{array}{l}\text { Imipenem } \\
\text { /Celestin }\end{array}$ & J01DH51 & Watch & 2 & 0.10 & 0.10 & 0.10 & 0.11 & 0.10 & 0.06 & 99.77 \\
\hline Vancomycin & J01XA01 & Watch & 1 & 0.06 & 0.04 & 0.19 & 0.11 & 0.10 & 0.06 & 99.83 \\
\hline Cephalexin & J01DB01 & Watch & 1 & 0.07 & 0.06 & 0.08 & 0.07 & 0.07 & 0.05 & 99.88 \\
\hline Teicoplanin & J01XA02 & Watch & 0.2 & 0.01 & 0.06 & 0.12 & 0.06 & 0.06 & 0.04 & 99.92 \\
\hline Meropenem & J01DH02 & Watch & 3 & 0.03 & 0.06 & 0.05 & 0.10 & 0.06 & 0.04 & 99.96 \\
\hline Cefpodoxime & J01DB03 & Watch & 1 & 0.02 & 0.03 & 0.01 & 0.05 & 0.03 & 0.02 & 99.97 \\
\hline Cefotaxime & J01DD01 & Watch & 1 & 0.00 & 0.00 & 0.04 & 0.03 & 0.02 & 0.01 & 99.99 \\
\hline Cefazolin & J001DB02 & Watch & 3 & 0.00 & 0.02 & 0.00 & 0.00 & 0.01 & 0.00 & 99.99 \\
\hline Ceftazidime & J01DD02 & Watch & 1 & 0.00 & 0.00 & 0.01 & 0.01 & 0.01 & 0.00 & 99.99 \\
\hline Tigecycline & J01AA12 & Reserve & 0.2 & 0.00 & 0.00 & 0.01 & 0.01 & 0.00 & 0.00 & $\begin{array}{l}100.0 \\
0\end{array}$ \\
\hline $\begin{array}{l}\text { Cefoperazone } \\
\text { +sulbactam }\end{array}$ & J01DD62 & Reserve & 1 & 0.00 & 0.00 & 0.01 & 0.00 & 0.00 & 0.00 & $\begin{array}{l}100.0 \\
0\end{array}$ \\
\hline $\begin{array}{l}\text { Netilmicin } \\
\text { Sulphate }\end{array}$ & JO1GH31 & Watch & 4 & 0.00 & 0.00 & 0.00 & 0.01 & 0.00 & 0.00 & 100 \\
\hline Minocycline & J01AA08 & Reserve & 0.2 & 0.00 & 0.00 & 0.00 & 0.00 & 0.00 & 0.00 & 100 \\
\hline $\begin{array}{l}\text { Chloramphenic } \\
\text { ol }\end{array}$ & J01BA01 & Access & 1 & 0.00 & 0.00 & 0.00 & 0.00 & 0.00 & 0.00 & 100 \\
\hline $\begin{array}{l}\text { Colistimethate } \\
\text { Sodium } \\
\text { powder }\end{array}$ & A07AA10 & Reserve & 1 & 0.00 & 0.00 & 0.00 & 0.00 & 0.00 & 0.00 & 100 \\
\hline Polymyxin B & A07AA05 & Reserve & 0 & 0.00 & 0.00 & 0.00 & 0.00 & 0.00 & 0.00 & 100 \\
\hline Total & & & 52.34 & 140.29 & 156.07 & 201.55 & 131.8 & 157.44 & & \\
\hline
\end{tabular}

\section{Drug utilization 90\% (DU 90\%) using DDD methodology}

Here, (Table 1) depicts the antibiotics (J01) procurement pattern using DDD and DU90\% methodology to interpret the change in utilization pattern over the year 2016-2019. (Figure 1). depicts mean antibiotic procurement increased 1.25 folds from 140.3 DDD in 2016 to 201 DDD in 2018. A significant fall was seen in total DDDs in year 2019 (p value $<0.05$ ). A total of 41 antibiotics agents (Access 12, Watch 21, Reserve 6 and Not recommended 2) were procured. Reserve category antibiotics were procured from 2017 onwards. Out of 41 antibiotics procured 11 antibiotics (Access 3 and watch 8) accounted for DU $90 \%$. In Figure 2 order of procurement was highest for Amoxycillin (16.15\%), azithromycin (12.94\%), ciprofloxacin $(12.88 \%)$, combination of amoxicillin and clavulanic acid $(12.46 \%)$, doxycycline $(9.95 \%)$, Cefixime $(8.72 \%)$, ceftriaxone $(8.28 \%)$, erythromycin (as Stearate) (2.60\%), ofloxacin (2.42\%), norfloxacin (2.21\%), levofloxacin $(1.85 \%)$.

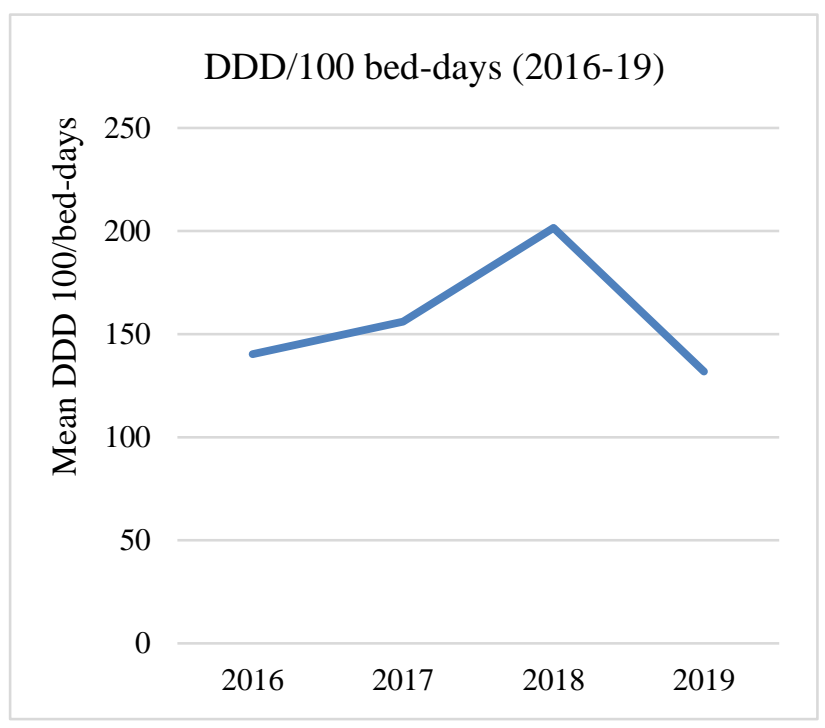

Figure 1: Antibiotic Consumption rate in wards from 2016 to 2019 in mean DDD/100 bed-days. 


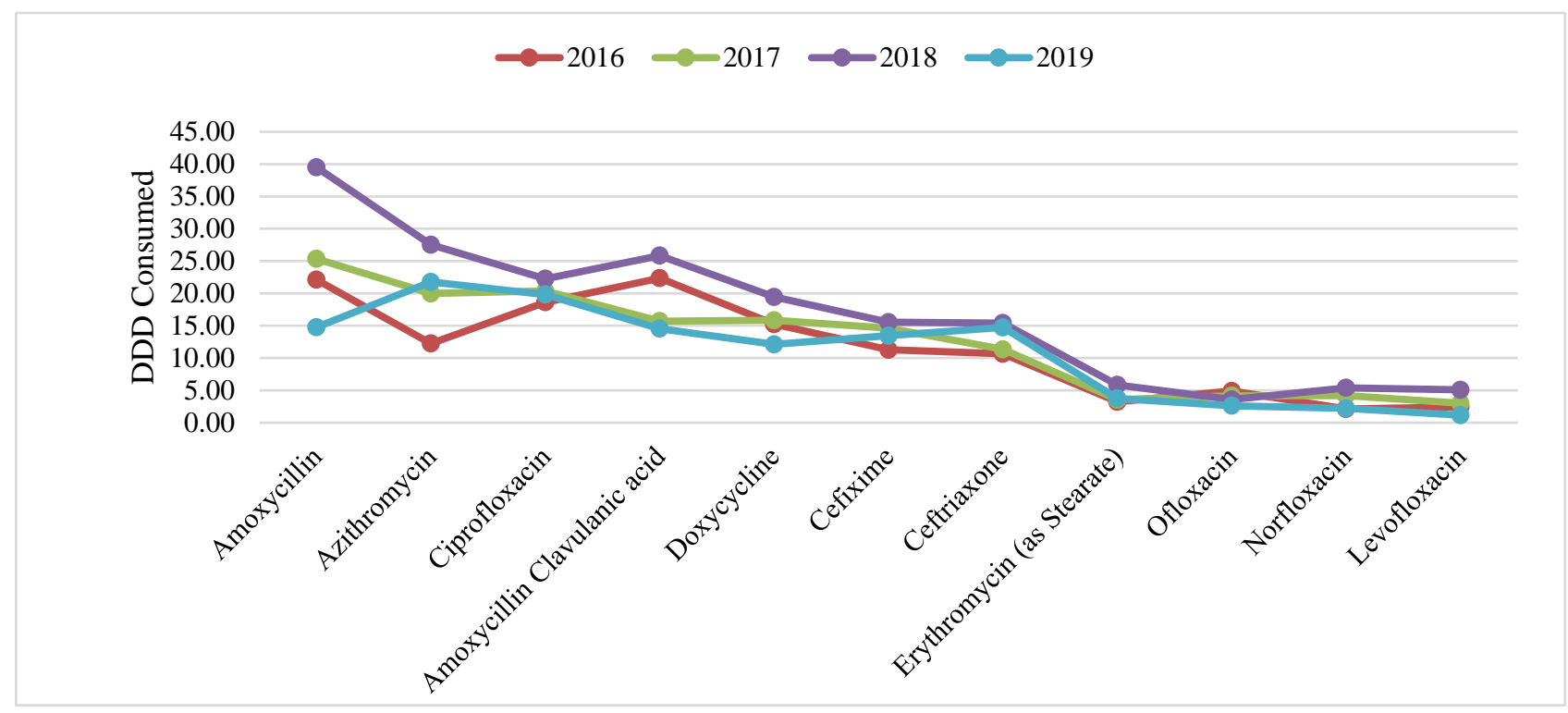

Figure 2: Drug utilization $90 \%$ based on DDD consumed.

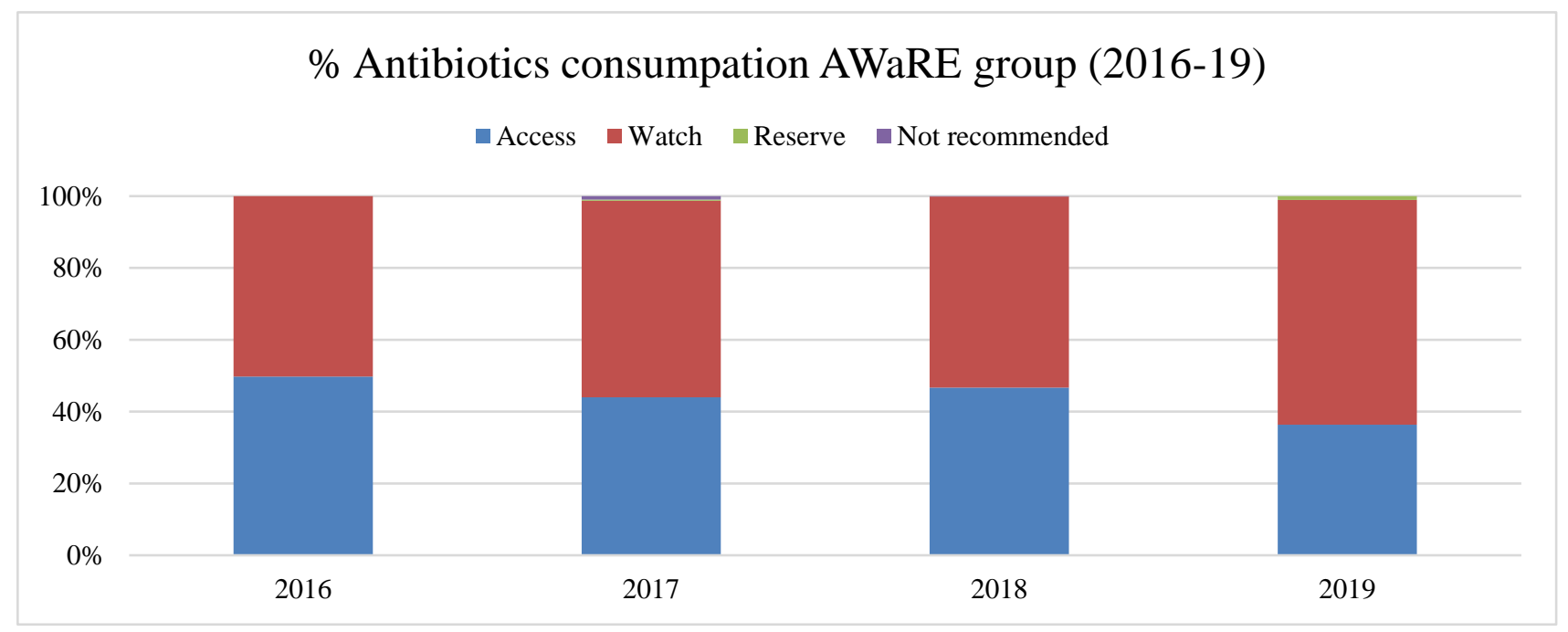

Figure 3: Percentage DDD consumption.

\section{AWaRe}

Figure 3. depicts the percentage of antibiotic procurement trend by DDD and AWaRe classification showing a significant increase in the use of Watch group antibiotics $63.23 \%$ (average $44.2 \%$ ) in 2019 from $50.57 \%$ in 2016 $\left(\mathrm{R}^{2}=0.78, \mathrm{p}=0.043\right)$, while a decrease in the use of access group from $49.43 \%$ (average $=55.2$ ) in 2016 to $35.6 \%$ in $2019\left(\mathrm{R}^{2}=0.74, \mathrm{p}=0.031\right)$ was observed. A significant rise in procurement of a reserve group antibiotic was seen from $0.11 \%$ in 2017 to $1.47 \%$ in the year 2018 . Three Not-recommended fixed dose combination antibiotics namely combination of ciprofloxacin and tinidazole, ofloxacin and ornidazole, cefoperazone and sulbactam, were also procured in the 2017. No DDD was assigned by WHO for Not-recommended fixed dose combination in EML list 2019. However, their procurement declined in 2018 to $0.19 \%$ from $2.01 \%$ in 2017.

\section{DISCUSSION}

The antibiotic procured was classified using AWaRe classification and there DDD is calculated using DDD methodology and then DU90\% measured using average DDD of 4-year in tertiary care center.

During our 4-year analysis we observed a significant 1.25 times increase in the DDD of antibiotics. Our figures are higher than the 108.5 DDDs/ 100 bed-days \& $113 .{ }^{9}$ DDDs/ 100 bed days reported by Shankar et al 2015, Handayal et al. 2019.,

In the present study, it was found that most of the prescribed antibiotics in DU-90\% had 8 drugs from Watch group and have a DDD much higher than the DDD recommended by WHO. Glycopeptides, penicillin like antibiotics and carbapenems had a DDD lower than the 
recommended DDD. These findings of the current study are comparable to results of other previous studies. Gidamudi et al and Sharma et al. 2018. ${ }^{7,8}$

Over the years procurement of Access group antibiotics declined by $20 \%$ and there was an increase watch group consumption. WHO goal is to target that $60 \%$ of all antibiotic's procurement should be from access group, 9 but unfortunately in our study, that trend is going in opposite direction. Focus of this aware tool is to guide prescribers to prescribe narrower spectrum antibiotics compared to other watch and reserve AWaRe categories to prevent resistance. ${ }^{10}$

Our access-to-watch index is less $<1$ in 2019. Reserve antibiotics were introduced lately and their use is very limited but increasing trend was observed. Similar finding was found in a study by Hsia et al.11

One limitation in the measurement of antibiotic procured in DDDs/100 bed-days is its inability to adjust antibiotic use according to variations in the case mix over time. The high antibiotic procurement rate in our hospital is possibly due to a higher case mix index (CMI). CMI is an economic parameter that is calculated using diagnosis related groups, a measure that is today routinely used in various countries as a basis for hospital reimbursement. Kuster et al. ${ }^{12}$

The other reason for high antibiotic procurement may be because of high antimicrobial resistance and thus the tendency to treat infection with broad spectrum antibiotics from watch and reserve group. There is variable situation regarding antibiotics prescribing and emergent of important opportunistic pathogens in every institute. Increase in antibiotic procurement is associated with significant antimicrobial resistance and increase number of blood cultures performed over the year and thus increase in isolation rate.

A significantly high rising trend of third-generation cephalosporin, fluoroquinolones and macrolides antibiotics was seen in procurement from watch category. Penicillin, a narrow spectrum antibiotic is a better option but is not being used because of poor availability. Similar patterns in antibiotics procurement found in study of Barker et al, Gandara $S$ et al Our result show parallel rise in resistance pattern $(100 \%$ in pseudomonas \& $87 \%$ in klebsiella). ${ }^{13,14}$ Similar trend of high resistance was reported by NCDC, Walia et al. 2019. ${ }^{15}$

The carbapenem class of antibiotics is one of the widely used antibiotics to treat serious bacterial infections. Our results showed no significant changes in procurement pattern.

Antibiotic FDCs are prevalent although there is no evidence to justify use of these combinations. Injudicious use of antibiotic FDCs could lead to emergence of bacterial strains resistant to multiple antibiotics.
Approximately 118 antibiotic FDCs are available in India (Ahmad et al 2016; Shankar et al 2016). ${ }^{16,17}$ The use of the fixed-dose combinations of multiple broad-spectrum antibiotics listed in not-recommended group of WHO essential drug list is not evidence-based, nor recommended in high-quality international guidelines. WHO does not recommend their use in clinical practice. ${ }^{18}$

Our finding indicates that the use of watch antibiotic consumption shows a significant increase in consumption than access group over 4 years, which reflects changes in antibiotic selection and challenges in improving antibiotics use. Prescribers should follow the published treatment guidelines by national center for disease control (NCDC) and IndiaCLEN taskforce, recommending more use of Access group of antibiotics in outpatients and inpatients settings.19 Third generation cephalosporins and carbapenems belong to watch group should be reserved for sick patients or patients admitted to ICU or clinical deterioration on first line agents belonging to Access group.

\section{Limitation}

Procurement data is used as proxy for consumption considering that same has been dispensed to the patient this might not always reflect the actual amount consumed by the patients. However, in this inherent limitation of the study, we believe that the methodology adopted would be more than adequate to give a clue to the antibiotic consumption rate using a standardized metrics.

\section{CONCLUSION}

Antibiotics consumption of Watch group was high and increasing antibiotic consumption trend was observed. Hospital antimicrobial stewardship program should be implemented to shift to use of Access group antibiotics and restrict use of Watch antibiotics. Further studies which focus on antibiotics categorization and consumption patterns need to be conduct, which would be instrumental in setting up a antibiotic's stewardship at

\section{ACKNOWLEDGEMENTS}

We are grateful to pharmacy staff of medical store of Saraswathi hospital for their cooperation in this investigation.

Funding: No funding sources

Conflict of interest: None declared

Ethical approval: Not required

\section{REFERENCES}

1. Klein EY, Van Boeckel TP, Martinez EM, Pant S, Gandra S, Levin SA, et al. Global increase and geographic convergence in antibiotic procurement between 2000 and 2015. Proc Natl Acad Sci. 2018:201717295. 
2. McElnay JC, Scott MG, Sidara JY, Kearney P. Audit of antibiotic usage in a medium-sized general hospital over an 11-year period. The impact of antibiotic policies. Pharm World Sci. 1995;17:20713.

3. MacDougall C, Polk RE. Antimicrobial stewardship programs in health care sys-tems. Clan Microbial Rev. 2005;18:638-56.

4. Sharland M, Pulcini C, Harbarth S, Zeng M, Gandra S, Mathur S, Magrini N. Classifying antibiotics in the WHO essential medicines list for optimal use-be AWaRe. Lanc Infect Dis. 2018;18(1):18-20

5. Handyal H, Kumar G, Chowdary PA, Jayasree V, Rathinavelu MR. Drug utilization research of antibiotics in an intensive care unit: a retrospective study from a rural healthcare setting in south india. Int J Scientif Resear. 2019;8(5):2019

6. Gidamudi SS, Jadhav SA, Khanwelkar CC, Thorat VM, Desai RR, Naik HG. Drug utilization study on antimicrobial use in urinary tract infection. Nation $\mathrm{J}$ Medic Resear. 2015;5(3):216-21.

7. Sharma A, Oommen S. Drug utilization pattern and physician adherence to treatment guidelines in inpatients with urinary tract infection. Int J Basic Clin Pharmacol 2018;7:363-9.

8. World Health Organization. WHO Report on Surveillance of Antibiotic Procurement: 2016-2018 early Implementations. Available at: https://www.who.int/medicines/areas/rational_use/o ms-amr-amc-report-2016-2018/en/. Accessed on 20 May 2020.

9. World Health Organization. Aware Portal. Available from: https://adoptaware.org. Accessed on 25 May 2020.

10. Hsia Y, Sharland M, Jackson C, Wong IC, Magrini N, Bielicki JA. Procurement of oral antibiotic formulations for young children according to the WHO access, watch, reserve (AWaRe) antibiotic groups: An analysis of sales data from 70 middleincome and high-income countries. Lancet Infect Dis. 2019;19:67-75.

11. Kuster SP, Ruef C, Bollinger AK, Ledergerber B, Hintermann A, Deplazes $\mathrm{C}$, et al. Correlation between case mix index and antibiotic use in hospitals. J Antimicrob Chemother. 2008;62(4):83742.
12. Gandra S, Kotwani A. Need to improve availability of "access" group antibiotics and reduce the use of "watch" group antibiotics in India for optimum use of antibiotics to contain antimicrobial resistance. $\mathrm{J}$ of Pharm Policy and Pract. 2019;12:20.

13. Barker AK, Brown K, Ahsan M, Sengupta S, Safdar N. Social determinants of antibiotic misuse: a qualitative study of community members in Haryana, India. BMC Pub Heal. 2017;17(1):333.

14. Walia K, Madhumathi J, Veeraraghavan B, Chakrabarti A, Kapil A, Ray P, et al. Establishing antimicrobial resistance surveillance \& research network in India: journey so far. Ind J Medic Resear. 2019;149(2):164.

15. Gandra S, Mojica N, Klein EY, Ashok A, Nerurkar $\mathrm{V}$, Kumari $\mathrm{M}$, et al. Trends in antibiotic resistance among major bacterial pathogens isolated from blood cultures tested at a large private laboratory network in India, 2008-2014. Int J Infect Diseas. 2016;50:7582.

16. Goel N, Wattal C, Oberoi JK, Raveendran R, Datta S, Prasad KJ. Trend analysis of antimicrobial procurement and development of resistance in nonfermenters in a tertiary care hospital in Delhi, India. J Antimicrob Chemother. 2011;66(7):1625-30.

17. Shankar PR, Hassali MA, Shahwani NA, Iqbal Q, Anwar M, Saleem F. Responsible use of fixed-dose combination antibiotics in India. Lanc Glob Heal. 2016;4(10):e689.

18. WHO. Medicines. WHO releases the 2019 AWaRe Classification Antibiotics. Available at: https://www.who.int/medicines/news/2019/WHO_rel eases2019AWaRe_classification_antibiotics/en/. Accessed on 05 May 2020.

19. NCDC. Index 1. National Programme on Containment of Anti-Microbial Resistance (AMR). Available at: https://ncdc.gov.in/index1.php. Accessed on 07 May 2020.

Cite this article as: Bhardwaj A, Kapoor K, Singh $\mathrm{V}$. Trend analysis of antibiotics consumption using WHO AWaRe classification in tertiary care hospital. Int J Basic Clin Pharmacol 2020;9:1675-80. 